\title{
Factors predictive of abnormal semen parameters in male partners of couples attending the infertility clinic of a tertiary hospital in south-western Nigeria
}

\author{
O P Aduloju, ${ }^{1}$ FWACS; P T Adegun, ${ }^{2}$ FMCS \\ ${ }^{1}$ Department of Obstetrics and Gynaecology, Faculty of Clinical Sciences, College of Medicine, Ekiti State University, Ado-Ekiti, Nigeria \\ ${ }^{2}$ Division of Urology, Department of Surgery, Faculty of Clinical Sciences, College of Medicine, Ekiti State University, Ado-Ekiti, Nigeria
}

Corresponding author: O P Aduloju (peter.aduloju@yahoo.com)

Background. Infertility is a common gynaecological problem and male factors contribute significantly to its aetiology. Semen analysis has remained useful for investigation of male factor infertility.

Objective. To assess the pattern of semen parameters, and predictive factors associated with abnormal parameters, in male partners of infertile couples attending a Nigerian tertiary hospital.

Methods. A descriptive study of infertile couples presenting at the clinic between January 2012 and December 2015 at Ekiti State University Teaching Hospital, Ado-Ekiti, Nigeria was done. Seminal fluid from the male partners was analysed in the laboratory using the World Health Organization 2010 criteria for human semen characteristics. Data were analysed using SPSS 17 and logistic regression analysis was used to determine the predictive factors associated with abnormal semen parameters.

Results. A total of 443 men participated in the study and $38.2 \%$ had abnormal sperm parameters. Oligozoospermia (34.8\%) and asthenozoospermia (26.9\%) were the leading single-factor abnormalities found, and astheno-oligozoospermia occurred in $14.2 \%$ and oligoasthenoteratozoospermia in $3.6 \%$ of cases. The prevalence of azoospermia was $3.4 \%$. Smoking habit, past infection with mumps and previous groin surgery significantly predicted abnormal semen parameters ( $p=0.025,0.040$ and 0.017 , respectively). Positive cultures were recorded in $36.2 \%$ of cases and Staphylococcus aureus was the most common.

Conclusion. Male factor abnormalities remain significant contributors to infertility and men should be encouraged, through advocacy, to participate in investigations into infertility, to reduce stigmatisation and ostracising of women with infertility, especially in sub-Saharan Africa.

S Afr J Obstet Gynaecol 2016;22(2):57-61. DOI:10.7196/SAJOG.2016.v22i2.1082

Infertility is a common gynaecological problem and is one of the most common reasons for consultations in gynaecological clinics. Over $80 \%$ of laparoscopic investigations are performed for infertility management. ${ }^{[1-3]}$ and infertility remains a sensitive issue in our environment and a source of social stigma. ${ }^{[1,4]}$ The burden of this stigma is felt more by female partners, who are often perceived as responsible for infertility and are faced with the challenges of economic deprivation, social neglect, marital instability, emotional stress and unhappiness. ${ }^{[1,5]}$

Infertility is a global problem with a variation in prevalent rate between regions. Worldwide, infertility is generally quoted as occurring in $8-15 \%$ of all couples, ${ }^{[3,6]}$ while in sub-Saharan Africa a prevalent rate of 15 - 45\% has been variously reported. ${ }^{[1,3,7]}$ However in Nigeria, reports from earlier studies have given an incidence of $20-30 \% \cdot{ }^{[7,8]}$

Infertility is an underlying pathology, with female factors contributing $30-40 \%$ of causes, male factors about $30-40 \%$, and both factors and unexplained infertility accounting for $20-40 \%$ of causes. $^{[3,6,7,9,10]}$

The aetiology of male infertility is largely unknown in most cases. ${ }^{[7,11]}$ However, studies have shown upward trends in the prevalence of sexually transmitted and urogenital infections. Semi- nal tract infections play a major contributory role in male infertility, affecting fertility through a number of different mechanisms, including impairment to spermatogenesis and sperm function, and obstruction of the seminal tract. ${ }^{[6,10-12]}$ Other factors that may lead to male infertility include varicocele, endocrine disturbance, immunological conditions, sexual dysfunction and ejaculatory failure. ${ }^{[7,11]}$

Semen analysis has remained a useful investigation in the search for male factor infertility and provides insight into the process of sperm production count, and sperm quality-motility and morphology ${ }^{[3,6,8,9]}$ The semen parameters have been found an important determinant of functional competence of the spermatozoa. ${ }^{[12,13]}$ Therefore, careful evaluation of these parameters may point to the possible causes of abnormal semen parameters and male infertility. This would enable the institution of appropriate treatment targeted at the identified aetiological factors.

Most previous studies on semen pattern have been based on the World Health Organization (WHO) 1999 criteria for human semen characteristics; $;^{[1,4-7,9]}$ however, there is a paucity of recent studies using the WHO 2010 criteria. $^{[3,14]}$

This study was conducted to assess the pattern of semen parameters in male partners of infertile couples attending the 
gynaecological clinic of Ekiti State University Teaching Hospital, Ado-Ekiti, Nigeria using the recent WHO 2010 criteria for semen characteristics to identify the contribution of male factors to the burden of infertility in our environment.

\section{Materials and methods Subjects}

The study was a descriptive evaluation of seminal fluid of male partners of infertile women presenting at the gynaecological clinic of Ekiti State University Teaching Hospital, Ado-Ekiti between January 2012 and December 2015. The male partners of infertile women who presented at the clinic were invited to the clinic through the women and a total of 443 consecutively consenting male partners of women with infertility were recruited.

\section{Sample collection}

A semistructured questionnaire with two sections was used to record information from the participants elicited by house officers and nursing staff of the gynaecological clinic. The first section reported the sociodemographic characteristics of the participants in terms of age, educational status, religion, occupation, marital status, family setting, type of infertility, duration of infertility, history of smoking and alcohol intake, history of childhood mumps infection, past history of chronic medical conditions such as diabetes mellitus, and past history of groin surgery such as herniorrhaphy or hydrocelectomy. In the second section the results of semen analysis in terms of volume, concentration, count, motility, morphology, period of continence and method of collection were recorded. The male partners were adequately counselled and given instructions on how to collect the semen sample. Instructions included abstinence from coitus for 3 - 5 days, washing of their hands before starting masturbation, and sample collection by masturbation only, kept close to the body and delivered to the hospital laboratory within 15 20 minutes of semen collection if not collected in the laboratory. Spilled samples were avoided. Samples were collected into sterile screw-capped plastic universal containers.

The semen samples were collected in a dedicated room with bed and other facilities to promote relaxation within the laboratory, while participants living close to the hospital were allowed to collect at home, bringing the samples to the hospital within 15 - 20 minutes of collection.

\section{Laboratory methods}

The semen analysis was performed according to the methods and standards outlined by the WHO 2010. ${ }^{[15]}$ The parameters assessed included volume $1.5 \mathrm{~mL}$ or more; sperm concentration $>15 \times 10^{6}$ cells $/ \mathrm{mL}$; motility $>40 \%$ progressive/forward movement; morphology $>4 \%$ normal form; and white blood cell count $1 \times 10^{6}$ cells $/ \mathrm{mL}$.

The sample analysis was done by the same laboratory scientist to avoid inter-laboratory variation, within 1 hour of collection. The sample was assessed for volume, appearance, liquefaction, concentration, motility, morphology, viability and presence of pus cells. The semen volume was measured using a graduated disposable pipette and $\mathrm{pH}$ checked with $\mathrm{pH}$ paper. After liquefaction, the semen specimen was thoroughly mixed using a pipette and a thin drop of specimen was spread on a glass slide by placing a cover slip on it. Sperm motility was assessed using an Olympus binocular microscope, magnification $\times 100$, while the sperm concentration was counted in millions per $\mathrm{mL}$ using the Meckler counting chamber
Table 1. Sociodemographic characteristics of male participants involved in the study

\begin{tabular}{ll}
\hline Characteristic & $n(\%), N=\mathbf{4 4 3}$ \\
\hline $\begin{array}{l}\text { Age group (years) } \\
\leq 30\end{array}$ & $55(12.4)$ \\
$31-35$ & $216(48.8)$ \\
$36-40$ & $90(20.3)$ \\
$41-45$ & $55(12.4)$ \\
$46-50$ & $24(5.4)$ \\
$\geq 50$ & $3(0.7)$
\end{tabular}

Family setting

Monogamous $\quad 362(81.7)$

Polygamous $\quad 81(18.3)$

Educational level

Primary

$48(10.8)$

Secondary

$105(23.7)$

Tertiary

$290(65.5)$

Occupation

Clergy

$37(8.4)$

Teaching

$68(15.3)$

Trading

75 (16.9)

Artisan

84 (19.0)

Civil servant

$179(40.4)$

Social habits

Smoking

Yes

$41(9.3)$

No

$402(90.7)$

Alcohol

Yes

$18(4.1)$

No

425 (95.9)

Past infection with mumps

Yes

No

424 (95.7)

Chronic medical condition

Yes

No

409 (92.3)

Previous groin surgery

Yes

No

Type of infertility

Primary $72(16.3)$

Secondary

$371(83.7)$

Volume of semen $(\mathrm{mL})$

$\begin{array}{ll}<2.0 & 154(34.8) \\ \geq 2.0 & 289(65.2) \\ & \text { Range }\end{array}$

Mean (SD)

Age of male partner (years) $\quad 30-60 \quad 36.36(5.07)$

Duration of infertility (years)

$1-11$

$3.13(2.40)$

Volume of semen $(\mathrm{mL})$

$0.5-5.0$

$2.36(1.22)$

Period of abstinence (days)

$3-7$

$4.54(0.99)$

Sperm concentration $\left(10^{6} / \mathrm{mL}\right)$

$0-170$

$35.41(31.60)$

Total sperm count $\left(10^{6}\right)$

$0-510$

$90.36(97.44)$ 
and categorised in accordance with WHO normal and pathological ranges. Bacteriological tests were also carried out on the semen samples by culture on appropriate culture media at $37^{\circ} \mathrm{C}$ for 24 48 hours to detect bacterial pathogens, and positive samples were subcultured to determine the appropriate antibiotic sensitivity pattern.

\section{Operational definitions}

The operational definitions used were as follows:

- Normospermia: sperm count of $\geq 15$ million $/ \mathrm{mL}$

- Oligospermia: sperm count of $\leq 15$ million $/ \mathrm{mL}$

- Azoospermia: absence of spermatozoa in the ejaculate

- Asthenospermia: reduced sperm motility $<40 \%$

- Teratozoospermia: reduced sperm morphology $<4 \%$

- Oligoasthenoteratozoospermia (OAT): all variables abnormal

\section{Data analysis}

Data were analysed using SPSS software version 17 (SPSS Inc, USA) for frequency, mean and $\chi^{2}$ with the level of significance set at $p<0.05$. Logistic regression analysis was performed to determine the risk factors significantly associated with abnormal sperm concentration.

\section{Ethical considerations}

Ethical approval was obtained from the Ethics and Research Committee of Ekiti State University Teaching Hospital and verbal consent was obtained from each couple participating in the study, following explanation of the study objectives. Questionnaires were made anonymous and couples were at liberty to withdraw or refrain from the study without any consequence.

\section{Results}

A total of 443 men participated in the study. The analysis revealed that $274(61.8 \%)$ had normal and $169(38.2 \%)$ abnormal semen parameters.

The age range of participants was between 30 - 60 years, with a mean (standard deviation (SD)) of 36.36 (5.07) years and the majority (69.1\%) aged between 31 - 45 years. The duration of infertility was between $1-11$ years, with a mean of $3.13(2.40)$ years. A total of $72(16.3 \%)$ participants were investigated for a case of primary infertility while 371 (83.7\%) were investigated for secondary infertility. The period of abstinence ranged between 3 - 7 days, with a mean of 4.54 (0.99) days. The sociodemographic characteristics of the male partners are shown in Table 1.

Various risk factors were associated with abnormal semen parameters. These included occupation and smoking habit of participants, past infections with mumps and previous groin surgery ( $p=0.001,0.04,0.022$ and 0.004 , respectively). Alcohol habits and chronic medical conditions were not significantly associated ( $p=0.121$ and 0.469 , respectively) (Table 2 ).

Multivariate logistic regression showed that smoking habit, past infection with mumps (mumps orchitis) and previous groin surgery in the male participants were significantly associated with abnormal semen parameters ( $p=0.025,0.040$ and 0.017 , respectively) when controlled for multiple risk factors.

Table 2. Risk factors associated with abnormal sperm parameters

\begin{tabular}{|c|c|c|c|c|}
\hline \multirow[b]{2}{*}{ Variable } & \multicolumn{3}{|c|}{ Sperm concentration, $\boldsymbol{n}(\%)$} & \multirow[b]{2}{*}{$p$-value } \\
\hline & Low & Normal & Total & \\
\hline \multicolumn{5}{|l|}{ Occupation } \\
\hline Clergy & $3(8.1)$ & $34(91.9)$ & $37(8.4)$ & \multirow[t]{5}{*}{$0.001^{*}$} \\
\hline Teaching & $26(38.2)$ & $42(61.8)$ & $68(15.3)$ & \\
\hline Trading & $15(20.0)$ & $60(80.0)$ & $5(16.9)$ & \\
\hline Artisan & $57(67.9)$ & $27(37.1)$ & $84(19.0)$ & \\
\hline Civil servant & $68(38.0)$ & $111(62.0)$ & $179(40.4)$ & \\
\hline \multicolumn{5}{|l|}{ Smoking } \\
\hline Yes & $26(57.8)$ & $19(42.2)$ & $45(10.2)$ & \multirow[t]{2}{*}{$0.04^{*}$} \\
\hline No & $143(35.9)$ & $255(64.1)$ & $398(89.8)$ & \\
\hline \multicolumn{5}{|l|}{ Alcohol } \\
\hline Yes & $10(55.6)$ & $8(44.4)$ & $18(4.1)$ & \multirow[t]{2}{*}{0.121} \\
\hline No & $159(37.4)$ & $266(62.6)$ & $425(95.9)$ & \\
\hline \multicolumn{5}{|c|}{ Past infection with mumps } \\
\hline Yes & $12(63.2)$ & $7(36.8)$ & $19(4.3)$ & \multirow[t]{2}{*}{$0.022^{*}$} \\
\hline No & $157(37.0)$ & $267(63.0)$ & $424(95.7)$ & \\
\hline \multicolumn{5}{|c|}{ Chronic medical illnesses } \\
\hline Yes & $11(32.4)$ & $23(67.6)$ & $34(7.7)$ & \multirow[t]{2}{*}{0.469} \\
\hline No & $158(38.6)$ & $251(61.4)$ & $409(92.3)$ & \\
\hline \multicolumn{5}{|c|}{ Previous groin surgery } \\
\hline Yes & $26(57.8)$ & $19(42.2)$ & $45(10.2)$ & \multirow[t]{2}{*}{$0.004^{\star}$} \\
\hline No & $143(35.9)$ & $255(64.1)$ & $398(89.8)$ & \\
\hline
\end{tabular}


A total of $154(34.8 \%)$ participants produced seminal volume of $<2 \mathrm{~mL}$ while $289(66.9 \%)$ produced $>2 \mathrm{~mL}$ (Table 1 ). The various abnormalities occurring singly or in combinations are shown in Table 4.

Although seminal fluid abnormality was found throughout the age groups, it was higher in those aged 31 - 45 years (Table 5).

A total of 160 (36.2\%) samples cultured positive for organisms and Staphylococcus aureus was the most common organism isolated, accounting for $24.4 \%$ of organisms cultured (Table 6 ).

\section{Discussion}

The study found that $38.2 \%$ of investigated couples had abnormal semen parameters. This result is higher than findings at Ile-Ife and Ibadan in south-western Nigeria. ${ }^{[1,3]}$ but similar to that reported from Abakaliki in south-eastern Nigeria. ${ }^{[12]}$ Semen analysis revealed the various sperm abnormalities contributory to male factor infertility. Sperm abnormalities due to distortion in the spermatogenesis process may be pretesticular (hormonal), testicular (chromosomal) and post-testicular (disorder in transportation or ejaculation, or caused by infections etc). ${ }^{[3,6,8,12]}$ These abnormal parameters, occuring singly or in combination, impair fertility even with normal sperm concentration. The outcome of treatment of male factor infertility is dependent on the presence of these factors. It has been reported that prognosis is inversely proportional to the number of abnormal patterns, i.e. that having one factor abnormality is better than having two factors, and two factors better than three factors. ${ }^{[1,6,16]}$

The single-factor abnormalities of low sperm count oligozoospermia (34.8\%) and poor motility-asthenozoospermia (26.9\%) were leading factors in sperm parameter abnormality while teratozoospermia contributed $6.9 \%$. This corroborates findings reported by previous studies in this environment. ${ }^{[1,8,12]}$ However, the two-factor abnormality of astheno-oligozoospermia was recorded in $14.2 \%$ of cases, which is comparable with findings from Jos and Ile-Ife ${ }^{[3,16]}$ but lower than reported in Ibadan, ${ }^{[1]}$ and the three-factor abnormality OAT occurred in $3.6 \%$ of the participants, which is comparable with that reported from Ile-Ife ${ }^{[3]}$ but lower than figures reported from Jos and Ibadan. ${ }^{[1,17]}$ The presence of these factors is associated with poor outcome with the use of conventional methods in the treatment of infertile couples. However, with newer techniques and advancements in assisted reproduction and conception, which are gradually becoming more available in our environment, pregnancy can be achieved. ${ }^{[1,3,8,17]}$ The prevalence of azoospermia of $3.4 \%$ in this study compares well with the rate in the general male population but was lower than findings in previous studies. ${ }^{[3,5,6]}$ About $62 \%$ of male partners in this study had normal sperm concentration, while the mean sperm density was 35.41 $(31.60) \times 10^{6}$ cells $/ \mathrm{mL}$; this implies that not only is absolute sperm count a male factor infertility determinant, but other components such as motility and morphology are equally important. Hence, infertility is not only associated with low sperm count but rather defective sperm parameters or other factors such as female factors.

The majority of the male partners produced normal semen volume although $33.1 \%$ had a low semen volume. Mean semen volume was 2.36 (1.22) $\mathrm{mL}$. These values are comparable with earlier reports from studies by Butt et al., Nwafia et al. and Imam et al. ${ }^{[6,18,19]}$ The adequate volumes reported in this study may be related to the period of continence observed by the male partners before presenting for seminal analysis, which was between 3 - 7 days with a mean of 4.54 (0.99) days, and this reflects the importance of abstinence before seminal fluid collection for analysis. Studies have shown that prolonged abstinence is
Table 3. Multivariate logistic regression analysis with sperm concentration as dependent variable

\begin{tabular}{|c|c|c|}
\hline Variable & $\begin{array}{l}\text { AOR }(95 \% \mathrm{CI} \\
\text { for AOR) }\end{array}$ & $p$-value \\
\hline \multicolumn{3}{|l|}{ Smoking } \\
\hline Yes & 1 & \\
\hline No & $\begin{array}{l}0.479 \\
(0.252-0.911)\end{array}$ & $0.025^{*}$ \\
\hline \multicolumn{3}{|c|}{ Previous groin surgery } \\
\hline No & 1 & \\
\hline Yes & $\begin{array}{l}0.460 \\
(0.243-0.871)\end{array}$ & $0.017^{\star}$ \\
\hline \multicolumn{3}{|c|}{ Past infection with mumps } \\
\hline No & 1 & \\
\hline Yes & $\begin{array}{l}0.396 \\
(0.150-1.046)\end{array}$ & $0.040^{*}$ \\
\hline \multicolumn{3}{|c|}{ Occupation of male partner } \\
\hline Professional & 1 & \\
\hline Artisan & $\begin{array}{l}1.486 \\
(0.989-2.231)\end{array}$ & 0.056 \\
\hline
\end{tabular}

Table 4. Pattern of abnormal semen parameters results of couples involved in the study $(N=16)$

\begin{tabular}{ll}
\hline Seminal fluid analysis & $\boldsymbol{n}(\%)$ \\
\hline Oligozoospermia & $59(34.9)$ \\
Asthenozoospermia & $45(26.6)$ \\
Oligoasthenozoospermia & $24(14.2)$ \\
Teratozoospermia & $11(6.5)$ \\
Asthenoteratozoospermia & $10(5.9)$ \\
Oligoteratozoospermia & $7(4.2)$ \\
OAT & $7(4.2)$ \\
Azoospermia & $6(3.5)$
\end{tabular}

associated with increased sperm concentration, but does not necessarily improve morphology and motility. ${ }^{[3,6,20]}$

There was a positive culture in $36.2 \%$ of our cases, with S. aureus accounting for the greatest proportion, comparable with previous findings. ${ }^{[3,7,21,22]}$ This may reflect penile contamination of the semen during collection even though the participants were instructed to observe aseptic technique. It may also be due to male genital infection, an important aetiological factor in male infertility which may lead to distortion of the process of spermatogenesis, impairment of sperm function and obstruction of the seminal tract. This may be contributory to the abnormal semen parameters recorded in this study, among the other factors elucidated. . $^{[1,3,6,12,20]}$

Environmental factors such as exposure to heat and chemicals, lifestyle factors such as smoking and alcohol consumption, chronic medical conditions such as diabetes mellitus and thyroid disease, previous groin surgery, including herniorrhaphy or varicocelectomy, and past mumps infection have been demonstrated as having adverse effects on sperm parameters. ${ }^{[12,23]}$ Consistent with previous reports, ${ }^{[24-26]}$ this study demonstrated a significant association 
Table 5. Distribution of abnormal semen parameters by age group

\begin{tabular}{|c|c|c|c|c|c|c|}
\hline \multirow[b]{2}{*}{ Semen fluid analysis } & \multicolumn{6}{|c|}{ Age group of husband (years) } \\
\hline & $\leq 30$ & $31-35$ & $36-40$ & $41-45$ & $46-50$ & $\geq 51$ \\
\hline Azoospermia & 0 & 3 & 1 & 1 & 1 & 0 \\
\hline Oligozoospermia & 13 & 40 & 1 & 4 & 0 & 1 \\
\hline Teratozoospermia & 4 & 4 & 1 & 2 & 3 & 1 \\
\hline Asthenozoospermia & 4 & 21 & 6 & 9 & 3 & 2 \\
\hline Oligoteratozoospermia & 1 & 2 & 1 & 1 & 1 & 1 \\
\hline Oligoasthenozoospermia & 4 & 8 & 2 & 3 & 4 & 3 \\
\hline Asthenoteratozoospermia & 1 & 3 & 1 & 2 & 2 & 1 \\
\hline OAT & 1 & 2 & 1 & 2 & 1 & 0 \\
\hline
\end{tabular}

Table 6. Cultured organisms $(N=443)$

\begin{tabular}{ll}
\hline Organism & $n(\%)$ \\
\hline Staphylococcus aureus & $108(24.2)$ \\
Klebsiella spp. & $15(3.4)$ \\
Escherichia coli & $10(2.3)$ \\
Streptococcus spp. & $8(1.8)$ \\
Candida spp. & $6(1.4)$ \\
Multiple coliforms & $13(2.9)$ \\
No organism isolated & $283(63.8)$
\end{tabular}

between smoking habit, past infection with mumps (mumps orchitis) and past groin surgery and abnormal sperm parameters, although Okonofua et al. ${ }^{[26]}$ also reported a significant association with alcohol consumption, among other factors.

A total of $371(83.7 \%)$ couples involved in this study presented with secondary infertility, and $72(16.3 \%)$ had primary infertility. This is higher than figures reported in Ibadan and Ile-Ife $\mathrm{f}^{[1,3]}$ and reflects a growing pattern in the incidence of secondary infertility in this environment. This may be attributed to the significant contribution of obstruction of the female and male genital tract resulting from a high rate of genital infections in both female (postabortal sepsis, puerperal sepsis) and male partners in our setting. ${ }^{[1,6]}$

\section{Conclusion}

Male factor abnormalities remain significant contributors to infertility, as demonstrated in this study, and the importance of semen analysis cannot be overemphasised in the detection of sperm abnormalities. On the basis of this, society should particularly view infertility as a couple problem rather than ostracising women, and men should be encouraged to take up the challenge and present themselves for appropriate testing and treatment. Government should ensure the establishment of public centres for assisted reproduction, to bring this closer to the less privileged in the society and contribute to solving the challenges posed by male infertility.

Acknowledgements. The authors acknowledged the couples who participated in the study, and the laboratory scientists of the microbiology department of the hospital who assisted in the analysis of the semen samples.

\section{References}

1. Adeniji RA, Olayemi O, Okunlola MA, Aimakhu CO. Pattern of semen analysis of male partners of infertile couples at the University College Hospital, Ibadan. W Afr J Med 2003;22(3):243-249. http:// dx.doi.org/10.4314/wajm.v22i3.27959

2. Orhue A, Aziken M. Experience with a comprehensive university-hospital-based infertility program in Nigeria. Int J Gynaecol Obstet 2008;101(1):11-15. http://dx.doi.org/10.1016/j. ijgo.2007.09.034

3. Owolabi AT, Fasubaa OB, Ogunniyi SO. Semen quality of male partners of infertile couple in Ile-Ife, Nigeria. Nig J Clin Pract 2013;16(1):37-40. http://dx.doi.org/10.4103/1119-3077.106729

4. Umeora OJ, Igberase GO, Okogbenin SA, Obu ID. Cultural misconception and emotional burden of infertility in South-East Nigeria. Int J Gynaecol Obstet 2009;10:2. https://dx.doi. org $/ 10.5580 / 10 \mathrm{a}$

5. Jimoh AAA, Olawuyi TS, Omotoso GO, Oyewepo AO, Dare JK. Semen parameters and hormone profile of men investigated for infertility at Midland Fertility Centre, Ilorin, Nigeria. J Basic Appl Sci 2012;8(1):110-113. http://dx.doi.org/10.6000/1927-5129.2012.08.01.03

6. Butt F, Akran N. Semen analysis parameters: Experiences and insight into male infertility at a tertiary care hospital in Punjab. J Pak Med Assoc 2013;63(5):558-562.

7. Ugboma HAA, Obuna JA, Ugboma EW Pattern of seminal fluid analysis among infertile couples in a secondary health facility in south-eastern Nigeria. Res Obstet Gynaecol 2012;1(2):15-18. http:// dx.doi.org/10.5923/j.rog.20120102.01

8. Ojiyi EC, Dike EI, Anolue BU, Okendo C, Uzoma OI, Uzoma JI. Male factor subfertility at Imo State University Teaching Hospital, Orlu. Int J Gynaecol Obstet 2012;16(1):1-6.

9. Jajoo S, Kalyani KR. Prevalence of abnormal semen analysis in patients of infertility at a rural set up in Central India. Int J Reprod Contracept Gynaecol Obstet 2003;2(2):161-164. http://dx.doi. org/10.5455/2320-1770.ijrcog20130610

10. Shaikh AH, Khalique K, Tanq G, Soomro N. Pattern of semen abnormalities in couples with male factor infertility. Pak J Surg 2011;27(3):204-208.

11. Monavari SH, Vaziri MB, Khalili M, et al. Asymptomatic seminal infection of herpes simplex virus: Impact on male infertility. J Biomed Res 2013;27(1):56-61. http://dx.doi.org/10.7555/ jbr.27.20110139

12. Ugwuja EI, Ugwu NC, Ejikeme BN. Prevalence of low sperm count and abnormal semen parameters in male partners of women consulting at infertility clinic in Abakaliki, Nigeria. Afr J Reprod Health 2008;12(1):67-72.

13. Dohle GR. Inflammatory associated obstruction of the male reproductive tract. Andrologia 2003;35(5):321-324. http://dx.doi.org/10.1111/j.1439-0272.2003.tb00866.x

14. Chukwunyere CF, Awonuga DO, Ogo CN, Nwadike V, Chukwunyere KE. Pattern of seminal fluid analysis in male partners of infertile couples attending gynaecology clinic at Federal Medical Centre, Abeokuta. Niger J Med 2015;24(2):131-136.

15. World Health Organization. WHO laboratory manual for the examination and processing of human semen. 5th ed. Geneva: WHO, 2000:7-113.

16. Jarrow JP, Espeland MA, Lipshultz G. Evaluation of azoospermic patients. J Urol 1989;142(1):62-65

17. Imade GE, Sagar AS, Pam IOA, Ujah PH. Semen quality in male partners of infertile couples in Jos, Nigeria. Trop J Obstet Gynaecol 2000;17(1):24-26.

18. Nwafia WC, Igweh JC, Udebuani IN. Semen analysis of infertile Igbo males in Enugu, Eastern Nigeria. Niger J Physiol Sci 2006;21(1-2):67-70. http://dx.doi/org/10.4314/njps.v21i1.54254

19. Imam MEI, Siuf A, Mansour MM, et al. Semen analysis of infertile Sudanese males in Gezira State, Central Sudan. Sudanese J Pub Health 2009;4(3):340-344.

20. Ikechebelu JI, Adinma JI, Orie EF, Ikegwuonu SO. High prevalence of male infertility in South Eastern Nigeria. J Obstet Gynaecol 2003;23(6):657-659. http://dx.doi.org/10.1080/014436103100 01604475

21. Ekwere PD, Archibong EI, Bassey EE, Ekabua JE, Ekanem EI, Feyi-Waboso P. Infertility among Nigerian couples as seen in Calabar. Port Med Journ 2007;2(1):35-40. http://dx.doi.org/10.4314 phmedj.v2i1.38890

22. Ibekwe PC, Mbazor JO. Semen evaluation of infertile couples in Abakaliki, Nigeria. Ebonyi Med Journ 2002;1(1):33-37. http://dx.doi.org.10.4314/ebomed.vli1.41517

23. Weber RF, Dohle GR, Romijn JC. Clinical laboratory evaluation of male infertility. Adv Clin Chem 2005;40:317-364. http://dx.doi.org/10.1016/s0065-2423(05)40008-6

24. Bayasgalan G, Naranbat D, Radnaabazar J, Lhagvasuren T, Rowe J. Male infertility: Risk factors in Mongolian men. Asian J Androl 2004;6(4):305-311.

25. Chia SE, Lim ST, Tay SK, Lim ST. Factors associated with male infertility: A case control study of 218 infertile and 240 fertile men. Br J Obstet Gynaecol 2000;107(1):55-61. http://dx.doi/ org/10.1111/j.1471-0528.2000.tb11579.x

26. Okonofua FE, Menakaya U, Onemu SO, Omo-Aghoja LO, Bergstrom S. A case-control study of risk factors for male infertility in Nigeria. Asian J Androl 2005;7(4):351-361. http://dx.doi. org/10.1111/j.1745-7262.2005.00046.x 